\title{
Splenosis Mimicking as Rectal Bastrointestinal Tumor
}

Murali Mohan Soma, Sachin S. Marda, Sailesh Shrikande, Parul Shukla

From the Department of Surgery, Yashoda hospital, Hyderabad, India.

\section{Abstract:}

Splenosis is heterotopic autotransplantation of splenic tissue following trauma or splenectomy. A 54 years gentleman presented to outpatient department with history of pain while passing stools. Clinical examination and radiological investigations were inconclusive. Exploratory laparotomy revealed hypervascular bluish mass in rectovesical pouch. Histopathology of excised tissue was suggestive of splenic tissue. On retrospective analysis, patient gave history of splenectomy 35 years back. High index of suspicion for splenosis is needed in patients with history of splenic injury or trauma.

Key words: Splenosis, Splenectomy, Neoplasms, Laparotomy, Pelvis.

\section{Introduction}

Splenosis is heterotopic autotransplantation of splenic tissue after trauma and or splenectomy [1]. It is often confused with malignant lesion or tumour recurrence [2]. We are reporting a case of splenic tissue in pouch of Douglas, 35 years after splenectomy for traumatic splenic injury.

\section{Case Report}

A 54 year old gentleman presented with history of discomfort during defecation. He had history of splenectomy following road traffic accident at the age of 35 years. Contrast enhanced CT scan abdomen revealed a hypervascular mass in pelvis [Fig. 1]. Lower Gl endoscopy and virtual colonoscopy were suggestive of submucosal lesion, probably rectal gastrointestinal tumor or extrinsic compression on upper rectum [Fig.2]. Endoscopic biopsy was inconclusive. Patient was planned for exploration and excision of the lesion with a provisional diagnosis of rectal malignancy.

Operative findings revealed bluish discoloured hypervascular mass in recto-vesical pouch compressing rectum and bladder. Lesion was successfully excised with subserosal dissection of rectum without rupture [Fig.3,4]. Histopathology of excised specimen was suggestive of normal splenic tissue with both red and white pulp structures consistent with splenosis. Postoperative period was uneventful. Patient was asymptomatic on 6 weeks postoperative follow up.

Corresponding Author: Dr. Murali Mohan Soma

Email: muralimohan_soma@yahoo.co.in

Received: March 20, 2013 | Accepted: April 14, 2013 | Published Online: May 30, 2013

This is an Open Access article distributed under the terms of the Creative Commons Attribution License (creativecommons.org/licenses/by/3.0)

Conflict of interest: None declared | Source of funding: Nil | DOl: http://dx.doi.org/10.17659/01.2013.0037 


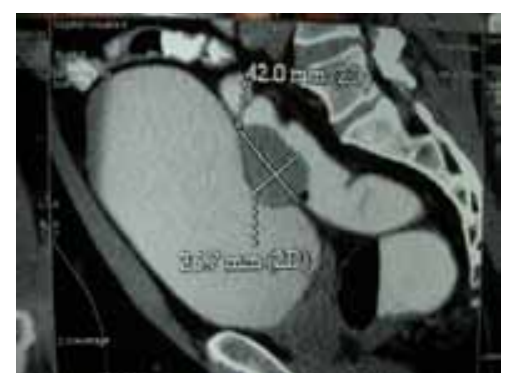

Fig.1: CT image revealed hypervascular mass in pelvis.

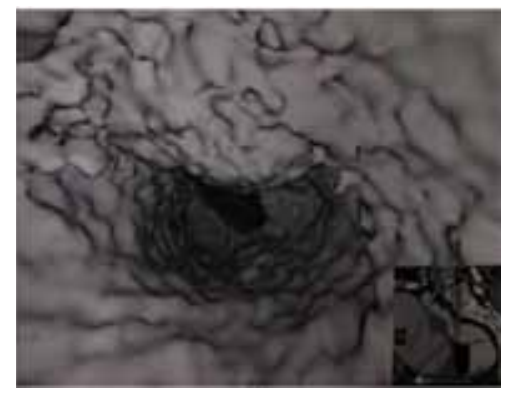

Fig.2: Virtual Colonoscopy suggestive of submucosal lesion.

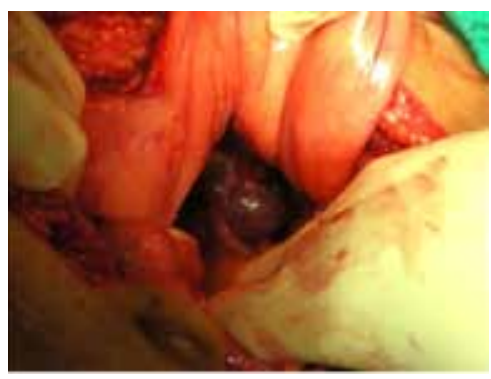

Fig.3: Operative photo showing mass lesion in rectovesical pouch.

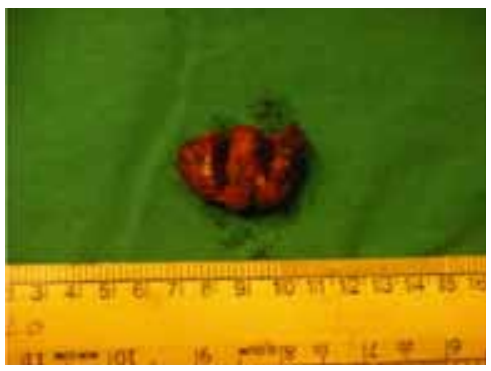

Fig.4: Post operative specimen. 


\section{Discussion}

Splenosis is defined as heterotrophic autotransplantation of splenic tissue after trauma and or removal of spleen [1]. This patient is a 54 years gentleman, presented with painful defecation. Clinical examination was clueless. Radiological imaging was inconclusive. On exploration of abdomen, splenic mass noticed in pouch of Douglas, was excised. He had history of splenic injury 35 years back for which he underwent splenectomy.

Prevalence of splenosis following trauma accounts for 16 to $67 \%$ [3], often seen in left upper quadrant, also in thoracic, retroperitoneal and even subcutaneously [2-7]. A case of cerebral splenosis was reported suggestive of haematogenous spread of splenic tissue [4]. It is easily mistaken for recurrent malignant lesion or disseminated metastasis. Various differential diagnosis for splenic tissue include suprarenal mass [5], renal mass, metastasis from transitional carcinoma [6], local recurrence after laparoscopic nephrectomy, endometriosis in female patient. Patients are usually asymptomatic, noticed incidentally during digital rectal examination, imaging or surgical exploration. Signs and symptoms depends on location of lesion and may include abdominal pain, haemoptysis, bleeding in body cavity or GI bleeding [7]. On CT scan appearance is multiple lesions with slow growth, irregular shape mimicking malignant tumour. Tc-99m heat damaged RBC radionuclide scan or Tc $99 \mathrm{~m}$ labelled sulphur colloid imaging is more sensitive and specific test to detect splenic implants [8]. Most of the patients do not require treatment unless symptomatic due to mass effect.

\section{Conclusion}

Autotransplantation of spleen occur can occur in parts of the body accessible for implantation. High index of suspicion is required in patients with history of splenic surgery. FNAC is often inconclusive. Treatment is seldom needed unless symptomatic.

\section{Competing Interests}

Author has no competing interest in this case.

\section{References}

1. Pisters PW, Pachter HL. Autologous splenic transplantation for splenic trauma. Ann Surg. 1994;219:225235.

2. Kwan AJ, Drum DE, Ahn CS, Tow DE. Intrathoracic Splenosis mimicking metastatic lung cancer. Clin Nucl Med.1994;19:93-95.

3. Wen-Chiung Lin, Rheun-Chaun Lee, Jen-Huey Chiang, Chao-Lung Wei, Lee-Shing Chu, ren-Shyan Liu, Cheng-Yen Chang. MR features of abdominal splenosis. Am J Roentgenol. 2003;180:493-496.

4. Rickert Christian H, Maasjosthusmann Ulrich, Probst-Cousin Stefan, August Christian, Gullota Filippo. A unique case of cerebral spleen. Am J Surg Pathol. 1998;22:894-896.

5. Kearns CM, Liu HY, Wollin M, Lepor H. Splenosis presenting as a left renal mass: a report of two cases. Eur Urol. 1994;26:264-266. 
6. Weinstein RP, Genega EM, and Dalbagni G. Splenosis mimicking transitional cell carcinoma. J Urol. 1999;161:1281.

7. Hibbeln JF, Wilbur AC, Schreiner VC, Trepashko DW. Subcutaneous splenosis. Clin Nucl Med. $1995 ; 20: 591-593$.

8. Zwas ST, Samra D, Samra Y, Sibber GR. Scintigraphic assessment of ectopic splenic tissue localization and function following splenectomy for trauma. Eur J Nucl Med. 1986;1 2:125-129. 